\title{
Impact of transanal endoscopic microsurgery on functional outcome and quality of life
}

\author{
P. G. Doornebosch • M. P. Gosselink • P. A. Neijenhuis • \\ W. R. Schouten - R. A. E. M. Tollenaar • \\ E. J. R. de Graaf
}

Accepted: 9 January 2008 /Published online: 1 April 2008

(C) Springer-Verlag 2008

\begin{abstract}
Introduction Transanal endoscopic microsurgery (TEM) is a minimal invasive technique for local excision of rectal tumours. The procedure is performed via a rectoscope with a diametre of $4 \mathrm{~cm}$. The aim of this prospective study was to assess both functional outcome and quality of life after TEM.

Patients and methods Between 2004 and 2006, 47 patients were studied prior to and at least 6 months after TEM. Demographics, operative details and post-operative complications were recorded. Functional outcome was determined using the Faecal Incontinence Severity Index (FISI). Quality of life was measured using the EuroQol EQ-5D questionnaire and the Faecal Incontinence Quality of Life (FIQL) score.

Results Six months after surgery, median FISI score was found to be decreased $(p<0.01)$, depicting an improvement in faecal continence. This improvement was most significant in tumours within $7 \mathrm{~cm}$ from the dentate line $(p=0.01)$. From the patients' perspective, post-operative quality of life was found to be higher $(p<0.02)$. A significant improve-
\end{abstract}

P. G. Doornebosch $(\bowtie) \cdot$ W. R. Schouten

Department of Surgery, Leiden University Medical Center,

Leiden, The Netherlands

e-mail: pgdoornebosch@hotmail.com

M. P. Gosselink • E. J. R. de Graaf

Department of Surgery, IJsselland Hospital,

Capelle aan den IJssel, The Netherlands

P. A. Neijenhuis

Department of Surgery, Rijnland Hospital,

Leiderdorp, The Netherlands

R. A. E. M. Tollenaar

Department of Surgery, University Medical Center,

Leiden, The Netherlands ment was observed in two of the four FIQLS domains (embarrassment, $p=0.03$; lifestyle, $p=0.05$ ). The domains of lifestyle, coping and behaviour and embarrassment were correlated with the FISI (all $p<0.05$ ).

Conclusion This study indicates TEM has no deteriorating effect on faecal continence. Moreover, once the tumour has been excised using TEM, quality of life is improved.

Keywords Rectal neoplasms · TEM - Local excision · Quality of life · Functional outcome

\section{Introduction}

Local excision of benign rectal tumours is safer compared to radical surgery and considered treatment of choice [1-3]. Several techniques have been developed for local excision, with the transanal technique according to Parks as the most frequently used $[1,4]$. Other techniques used are the dorsal transcoccygeal approach (Kraske) and the dorsal transsphincteric approach (York-Mason) [5-9]. Each procedure has its own (dis)advantages, and none of the procedures mentioned is able to achieve local excision of tumours throughout the entire rectum. Transanal endoscopic microsurgery (TEM) demonstrated to be a safe procedure capable of overcoming this shortcoming. In early publications, even distal sigmoid tumours could be locally excised with excellent results. Moreover, recurrence rates are minimal compared to other local techniques. As a result, the indication for local excision of rectal tumours has expanded dramatically [10-13].

Few studies have addressed functional outcome following TEM, and with the operation rectoscope with a length of 12 or $20 \mathrm{~cm}$ and a diametre of $40 \mathrm{~mm}$, scepticism towards post-operative faecal continence remains. In man- 
ometric studies after TEM, there seems to be a detrimental, temporary impact on internal sphincter functioning, although without clinical significance [14-16].

Cataldo et al. [17] recently performed a prospective study on faecal continence and incontinence-specific quality of life after TEM using standardised surveys. They stated TEM does not result in significant alterations. These results are promising, especially with a relative short duration of follow-up of 6 weeks in this study. As known from other types of rectal surgery, incidence of faecal incontinence diminishes with time [18]. This could imply results after TEM may even improve with longer follow-up.

Quality of life is increasingly recognised as the ultimate endpoint when assessing clinical outcomes after different surgical interventions because it measures the patient's perspective. The precise impact of the TEM procedure on quality of life has not been well studied. This prospective study was set out to provide a comprehensive insight into the impact of TEM on functional outcome and quality of life.

\section{Patients and methods}

Between January 2004 and January 2006, a consecutive series of 50 patients were referred for a TEM procedure. All patients were evaluated pre-operatively according to a standard protocol including rigid rectoscopy, tumour biopsy and endorectal ultrasound. If TEM was considered feasible, patients were eligible for this study. Informed consent had to be given before inclusion. Local medical ethical committees approved this study. A full-thickness excision was always performed. The portion of the tumour located within the sphincter musculature was excised in partial thickness. Before and at least 6 months after the TEM procedure, patients were asked to fill out a questionnaire to assess anorectal functioning and quality of life. All data were collected by an independent research coordinator not previously involved in the patients' care. We recorded the demographics, operative details, post-operative length of stay, post-operative complications and functional outcome for each participant. We evaluated functional outcome by means of a detailed questionnaire based on the Faecal Incontinence Severity Index (FISI) [19]. This system, developed by Rockwood, uses two basic components: the type of incontinence and its frequency. FISI scores range from 0 (total continence) to 61 (complete incontinence to solid stool on a daily basis). We used the validated weighting scores that are based on patients' input.

Quality of life was evaluated using both the EuroQol EQ-5D and the Faecal Incontinence Quality of Life (FIQL) score. The EuroQol EQ-5D consists of a so-called index score representing the societal value of the health state and has a scale ranging from 0 (no quality of life) to 100 (optimal quality of life). The EuroQol EQ-5D also uses a visual analogue scale, the EQ-VAS, representing the patient perspective. This scale ranges from 0 (no quality of life) to 100 (optimal quality of life). The EuroQoL EQ-5D scores were compared with a sex- and age-matched, communitybased sample of healthy persons without co-morbidity [20]. The FIQL score as described by Rockwood et al. [21] measures specific quality of life issues expected to affect patients with faecal incontinence. This instrument is composed of 29 questions within four domains: lifestyle issues, coping-behaviour, depression and self-perception and embarrassment. The scores in the FIQL range from a minimum score of 1 to a maximum of 4 , for all of the scales $(1=$ quality of life alteration present most of the time, $4=$ none of the time). Data are presented as medians and standard deviations. Changes within groups were evaluated using the nonparametric one-sample Wilcoxon's signedrank test. Comparison of these changes between groups was conducted using the Mann-Witney $U$ test. The Spearman's correlation coefficient was used for correlation between the different findings. A $P$-value of $\leq 0.05$ was considered statistically significant.

\section{Results}

Fifty patients were eligible and informed consent was obtained. Three patients were excluded. In two patients, TEM could not be performed because of bulky tumour or technical problems. An additional patient underwent lowanterior resection for locally recurrent disease within 6 months of the TEM. The remaining 47 patients completed both questionnaires and were included for analysis. All of these patients were alive without evidence of recurrent disease. The group consisted of 22 males and 25 females. Median age was 67 years (range 40-84). Pre-operative diagnosis was villous adenoma in all patients. Median distance from the distal tumour margin to the dentate line was $7 \mathrm{~cm}$ (range $0-15 \mathrm{~cm}$ ) and median tumour size was $20 \mathrm{~cm}^{2}$ (range $4-53 \mathrm{~cm}^{2}$ ). The median rate of captured circumference of the rectal wall was $40 \%$ (range 5-80; Table 1). Median operative time, defined as beginning

Table 1 Patient and tumour characteristics

\begin{tabular}{ll}
\hline Characteristics & Number \\
\hline Male/female $(N=47)$ & $22 / 25$ \\
Median age in years (range) & $67(40-84)$ \\
Median distance from dentate line in centimetres & $7(0-15)$ \\
$\quad$ (range) & $20(4-53)$ \\
Median tumour size in square centimetres (range) & $40(5-80)$ \\
Median capture of circumference of rectal & \\
$\quad$ wall in per cent (range) & \\
\hline
\end{tabular}


Table 2 Procedure-related characteristics

\begin{tabular}{ll}
\hline Characteristics & Number \\
\hline Median duration of operation in minutes (range) & $55(10-140)$ \\
Complications & $4 / 47(8.5 \%)$ \\
Urinary retention & 2 \\
Urinary tract infection & 1 \\
Blood transfusion & 1 \\
Reoperations & None \\
Length of hospital stay in days (range) & $4(3-9)$ \\
\hline
\end{tabular}

when the rectoscope was inserted and ending when it was removed, was $55 \mathrm{~min}$ (range 10-140). Complications developed in 4 of $47(8.5 \%)$ patients. Two patients had urinary retention, one patient a urinary tract infection and one suffered from a low hemoglobin rate requiring blood transfusion. No reoperations were necessary and mortality rate was zero. Median length of stay was 4 days (range 39 days; Table 2). Definite histopathological examination of the resected specimens revealed an adenoma in 44 patients and an invasive carcinoma in three patients (pT1 in two patients and pT2 in one patient). These three patients were reluctant to undergo major surgery and were observed with rectoscopy and endorectal ultrasound every 3 months without signs of recurrence at 6 months after TEM. In three adenomas, excisional margin was considered microscopic irradical, resulting in $94 \%$ of tumours being radically excised.

Six months after surgery, mean FISI scores were found to be decreased (pre-operative, 10; post-operative, 7 ( $p<$ $0.01)$ ), depicting an improvement in faecal continence (Fig. 1). Overall, when pre-operative and post-operative FISI scores were compared, 24 patients improved, 16 patients were unchanged and seven deteriorated. Operation time or tumour size did not influence the change in FISI score. There was a significant correlation between the decrease in FISI score and tumour height $(p=0.02)$. Reduction of FISI was significantly greater in patients with a tumour location within $7 \mathrm{~cm}$ from the dentate line $(p=$ 0.01; Table 3). Mean scores and ranges of the EuroQol EQ-

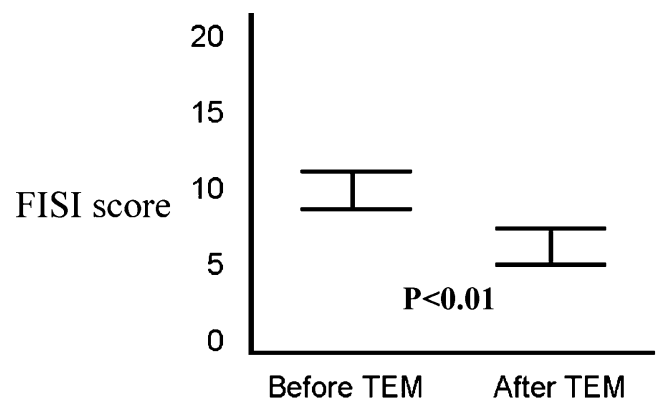

Fig. 1 Mean Faecal Incontinence Severity Index (FISI) scores $( \pm$ SEM) before and after Transanal Endoscopic Microsurgery (TEM)
Table 3 Mean FISI scores; numbers in parentheses are standard deviations

\begin{tabular}{lcll}
\hline FISI score & $\begin{array}{l}\text { Pre- } \\
\text { operative }\end{array}$ & $\begin{array}{l}\text { Post- } \\
\text { operative }\end{array}$ & $\begin{array}{l}\text { Statistical } \\
\text { significance }\end{array}$ \\
\hline $\begin{array}{l}\text { Overall } \\
\begin{array}{c}\text { Duration of operation } \\
\quad 55 \text { min }(N=24)\end{array}\end{array}$ & $9(2)$ & $6(2)$ & $p<0.01$ \\
$\begin{array}{c}\text { Duration of operation } \\
>55 \text { min }(N=23)\end{array}$ & $12(3)$ & $4(2)$ & $p=0.17$ \\
$\begin{array}{c}\text { Tumours }<7 \mathrm{~cm} \text { from } \\
\text { dentate line }(N=21)\end{array}$ & $16(5)$ & $5(2)$ & $p=0.01$ \\
$\begin{array}{c}\text { Tumours }>7 \mathrm{~cm} \text { from } \\
\text { dentate line }(N=26)\end{array}$ & $6(2)$ & $7(3)$ & $p=0.43$ \\
$\begin{array}{c}\text { Median tumour size } \\
<20 \mathrm{~cm}^{2}(N=27)\end{array}$ & $12(4)$ & $6(3)$ & $p=0.12$ \\
$\begin{array}{c}\text { Median tumour size } \\
>20 \mathrm{~cm}^{2}(N=20)\end{array}$ & $8(3)$ & $6(3)$ & $p=0.32$ \\
\hline
\end{tabular}

Lower values indicate better anorectal functioning

5D are presented in Table 4. Mean general quality of life score from the patients' perspective (EQ-VAS) was found to be significantly higher 6 months after TEM $(p<0.02)$. The observed changes in EQ-VAS showed no correlation with the post-operative alterations in FISI scores or tumour characteristics. Mean pre-operative EQ-VAS score in our group was lower compared to the mean EQ-VAS score of the sex- and age-matched general population $(p=0.02)$. Post-operative EQ-VAS score was comparable with the general population. Mean index score (social perspective) remained the same $(p=0.09)$. Both pre- and post-operative EQ-5D index scores were similar to those of the sex-agematched general population. Comparing the change from baseline in FIQL scores, a statistically significant improvement was observed in two of the four domains (embarrassment; $p=0.03$ and lifestyle; $p=0.05$ ). The domains of lifestyle, coping and behaviour and embarrassment were correlated with the FISI (all $p<0.05$; Table 5). Overall, EQ$5 \mathrm{D}$ and FIQL scores were not affected by age and gender of the patients. Surgical aspects and tumour characteristics did not influence the outcome.

Table 4 Mean EuroQoL EQ-5D scores; numbers in parentheses are standard deviations

\begin{tabular}{lccll}
\hline & $\begin{array}{l}\text { Control } \\
\text { group }\end{array}$ & $\begin{array}{l}\text { Pre- } \\
\text { operative }\end{array}$ & $\begin{array}{l}\text { Post- } \\
\text { operative }\end{array}$ & $\begin{array}{l}\text { Statistical } \\
\text { significance }\end{array}$ \\
\hline EQ-VAS & $82(7)$ & $77(14)$ & $82(11)$ & $p=0.02$ \\
Index score & $86(6)$ & $84(11)$ & $89(9)$ & $p=0.09$ \\
\hline
\end{tabular}

EQ-VAS represents the patients' perspective on quality of life; index score represents the societal value on quality of life. Higher scores indicate higher quality of life. Both scores are compared with a healthy sex- and age-matched control group. 
Table 5 Mean FIQL scores; numbers in parentheses are standard deviations

\begin{tabular}{llll}
\hline FIQLS & $\begin{array}{l}\text { Pre- } \\
\text { operative }\end{array}$ & $\begin{array}{l}\text { Post- } \\
\text { operative }\end{array}$ & $\begin{array}{l}\text { Statistical } \\
\text { significance }\end{array}$ \\
\hline Lifestyle & $3.7(0.3)$ & $3.9(0.3)$ & $p=0.05$ \\
Coping & $3.6(0.5)$ & $3.8(0.4)$ & $p=0.10$ \\
Depression & $3.7(0.3)$ & $3.9(0.4)$ & $p=0.08$ \\
Embarrassment & $3.1(0.3)$ & $3.7(0.4)$ & $p=0.03$ \\
\hline
\end{tabular}

Higher scores indicate higher quality of life.

\section{Discussion}

In rectal adenomas, TEM has emerged as the procedure of choice because of its safety and low local recurrence rates. Especially compared to radical surgery, TEM has proven its safety $[22,23]$. However, possible adverse effects of TEM have to be addressed. The use of a rectoscope with a $4-\mathrm{cm}$ diametre, introduced transanally, has lead to substantial scepticism regarding impact on anorectal functioning. In earlier studies, we already showed TEM to be superior to total mesorectal excision regarding post-operative defecation disorders, although this did not result in improved quality of life [24]. In the present study, TEM resulted in improved faecal continence as measured by the FISI. This apparent paradox may be attributed to pre-operative tumour symptoms such as mucinous or bloody discharge, prolapse, tenesmi and/or urge, giving rise to incontinence-like symptoms. Post-operative improvement of continence was most significant in tumours within $7 \mathrm{~cm}$ from the dentate line but disappeared in our study in tumours above $7 \mathrm{~cm}$ from the dentate line. Kreis et al. [25] performed manometric studies after TEM and found a significant reduction in anal resting pressure 1 year post-operative and a temporary reduction in anal squeezing pressure, resulting in a temporary rise in urge-incontinence. Kennedy et al. [26] found a significant reduction in anal resting pressure 6 weeks after TEM. This reduction was significantly correlated with duration of the procedure, but mean continence score was not changed after TEM. Both of the above studies however did not use validated questionnaires on faecal continence, and therefore comparison with our study is difficult. Cataldo et al. [17] reported on the impact of TEM on functional outcome and incontinence-specific quality of life using the same questionnaires. No significant alteration was found in faecal continence after TEM. The discrepancy between both studies may be explained by the relative short interval between the TEM procedure and post-operative questioning of 6 weeks in the Cataldo series. Also, in his study, indications for TEM were heterogeneous which may have influenced results. The positive effect of
TEM on faecal continence in our series may be explained by the differences in pre-operative FISI score between both studies (10 versus 2.4), depicting more continence problems among the patients in our series. Another explanation may be the differences in tumour distance from the dentate line (present series median $7 \mathrm{~cm}$, Cataldo series $11 \mathrm{~cm}$ ). Also, in our series, tumours were larger (median $20 \mathrm{~cm}^{2}$ versus $8.75 \mathrm{~cm}^{2}$ ). Because tumours were larger in our series, more extensive resections were performed, often in tumours located within the sphincter apparatus. These latter resections were already shown to influence rectoinhibitory reflex, reflex sphincter contraction, rectal sensitivity and compliance [16]. Further analysis within our series upon this issue showed only tumour distance from the dentate line of less than $7 \mathrm{~cm}$ to be a significant contributing factor. These results however are based upon low number of patients and therefore solid conclusions cannot be drawn. Although in our study TEM resulted in a significant improvement in continence, the post-operative FISI was still worse compared to the Cataldo series (7 versus 2.4). Regarding quality of life, Cataldo found TEM was of no significant influence. In our series, mean general quality of life score from the patients' perspective, EQ-VAS, was significantly higher after TEM. This improvement could not be explained by improved FISI scores but probably by lower pre-operative EQ-VAS scores as compared to healthy controls. Another explanation may be the rejoice phenomena, that is, patients are relieved the tumour has been excised, and in most cases an adenoma was found [27]. However, because of the low number of invasive carcinomas in our series this is purely theoretical. The societal value of general quality of life, EQ-5D, remained unchanged. Measuring quality of life using the FIQL questionnaires resulted in a significant improvement in two of the four FIQL domains (embarrassment and lifestyle). Moreover, the domains of lifestyle, coping and behaviour and embarrassment were all significantly correlated with the FISI.

In conclusion, how are these results to be interpreted? This study supports the hypothesis that rectal tumours give rise to incontinence-like symptoms, especially in low-lying rectal tumours. After the tumour is excised using the TEM technique, faecal continence improves. TEM itself does not improve continence but also does not deteriorate faecal continence. Mean quality of life from the patients' perspective following TEM is improved.

Based on, as we know, the only two studies addressing anorectal functioning and quality of life after TEM in one study, it can be concluded that TEM does not impair faecal continence. Also, quality of life is not negatively influenced by the TEM procedure itself, and therefore TEM is the procedure of choice in all rectal adenomas. 


\section{References}

1. Parks AG, Stuart AE (1973) The management of villous tumours of the large bowel. Br J Surg 60(9):688-695

2. Endreseth BH, Wibe A, Svinsas M, Marvik R, Myrvold HE (2005) Postoperative morbidity and recurrence after local excision of rectal adenomas and rectal cancer by transanal endoscopic microsurgery. Colorectal Dis 7(2):133-137

3. Winde G, Nottberg H, Keller R, Schmid KW, Bunte H (1996) Surgical cure for early rectal carcinomas (T1). Transanal endoscopic microsurgery vs. anterior resection. Dis Colon Rectum 39 (9):969-976

4. Pigot F, Bouchard D, Mortaji M, Castinel A, Juguet F, Chaume JC et al (2003) Local excision of large rectal villous adenomas: longterm results. Dis Colon Rectum 46(10):1345-1350

5. Terkivatan T, den Hoed PT, Lange JF Jr., Koot VC, van Goch JJ, Veen HF (2005) The place of the posterior surgical approach for lesions of the rectum. Dig Surg 22(1-2):86-90

6. Thompson BW, Tucker WE (1987) Transsphincteric approach to lesions of the rectum. South Med J 80(1):41-43

7. Schildberg FW, Wenk H (1986) Sphincter-preserving interventions in rectal tumors. The posterior approach to the rectum. Chirurg 57(12):779-791

8. Christiansen J (1980) Excision of mid-rectal lesions by the Kraske sacral approach. Br J Surg 67(9):651-652

9. Mason AY (1970) Surgical access to the rectum-a transsphincteric exposure. Proc R Soc Med Suppl 63:91-94

10. Buess G, Kipfmuller K, Hack D, Grussner R, Heintz A, Junginger $\mathrm{T}$ (1988) Technique of transanal endoscopic microsurgery. Surg Endosc 2(2):71-75

11. Buess G, Kipfmuller K, Ibald R, Heintz A, Hack D, Braunstein S et al (1988) Clinical results of transanal endoscopic microsurgery. Surg Endosc 2(4):245-250

12. Middleton PF, Sutherland LM, Maddern GJ (2005) Transanal endoscopic microsurgery: a systematic review. Dis Colon Rectum 48(2):270-284

13. Lin GL, Meng WC, Lau PY, Qiu HZ, Yip AW (2006) Local resection for early rectal tumours: comparative study of transanal endoscopic microsurgery (TEM) versus posterior trans-sphincteric approach (Mason's operation). Asian J Surg 29(4):227-232

14. Banerjee AK, Jehle EC, Kreis ME, Schott UG, Claussen CD, Becker HD et al (1996) Prospective study of the proctographic and functional consequences of transanal endoscopic microsurgery. Br J Surg 83(2):211-213
15. Hemingway D, Flett M, McKee RF, Finlay IG (1996) Sphincter function after transanal endoscopic microsurgical excision of rectal tumours. Br J Surg 83(1):51-52

16. Herman RM, Richter P, Walega P, Popiela T (2001) Anorectal sphincter function and rectal barostat study in patients following transanal endoscopic microsurgery. Int $\mathrm{J}$ Colorectal Dis 16 (6):370-376

17. Cataldo PA, O’Brien S, Osler T (2005) Transanal endoscopic microsurgery: a prospective evaluation of functional results. Dis Colon Rectum 48(7):1366-1371

18. Nyam DC, Pemberton JH (1999) Long-term results of lateral internal sphincterotomy for chronic anal fissure with particular reference to incidence of fecal incontinence. Dis Colon Rectum 42 (10):1306-1310

19. Rockwood TH, Church JM, Fleshman JW, Kane RL, Mavrantonis C, Thorson AG et al (1999) Patient and surgeon ranking of the severity of symptoms associated with fecal incontinence: the fecal incontinence severity index. Dis Colon Rectum 42(12):1525-1532

20. Kind P, Dolan P, Gudex C, Williams A (1998) Variations in population health status: results from a United Kingdom national questionnaire survey. BMJ 316(7133):736-741

21. Rockwood TH, Church JM, Fleshman JW, Kane RL, Mavrantonis C, Thorson AG et al (2000) Fecal Incontinence Quality of Life Scale: quality of life instrument for patients with fecal incontinence. Dis Colon Rectum 43(1):9-16, discussion 16-17

22. Heintz A, Morschel M, Junginger T (1998) Comparison of results after transanal endoscopic microsurgery and radical resection for T1 carcinoma of the rectum. Surg Endosc 12(9):1145-1148

23. Langer C, Liersch T, Suss M, Siemer A, Markus P, Ghadimi BM et al (2003) Surgical cure for early rectal carcinoma and large adenoma: transanal endoscopic microsurgery (using ultrasound or electrosurgery) compared to conventional local and radical resection. Int J Colorectal Dis 18(3):222-229

24. Doornebosch PG, Tollenaar RA, Gosselink MP, Stassen LP, Dijkhuis CM, Schouten WR et al (2007) Quality of life after transanal endoscopic microsurgery and total mesorectal excision in early rectal cancer. Colorectal Dis 9(6):553-558

25. Kreis ME, Jehle EC, Haug V, Manncke K, Buess GF, Becker HD et al (1996) Functional results after transanal endoscopic microsurgery. Dis Colon Rectum 39(10):1116-1121

26. Kennedy ML, Lubowski DZ, King DW (2002) Transanal endoscopic microsurgery excision: is anorectal function compromised? Dis Colon Rectum 45(5):601-604

27. Nord E (1989) The significance of contextual factors in valuing health states. Health Policy 13(3):189-198 